$05.2,06.5$

\title{
Нанокристаллы магнетита с повышенной константой магнитной анизотропии, наведенной формой частицы
}

\author{
() С.В. Столяр ${ }^{1-3}$, С.В. Комогорцев ${ }^{1-3}$, Л.А. Чеканова ${ }^{2}$, Р.Н. Ярославцев ${ }^{1,2}$, О.А. Баюков ${ }^{2}$, Д.А. Великанов ${ }^{2}$, \\ М.Н. Волочаев ${ }^{2}$, Е.В. Черемискина ${ }^{1}$, M.Sh. Bairmani ${ }^{4,5}$, П.Е. Ерошенко ${ }^{2}$, Р.С. Исхаков ${ }^{2}$ \\ ${ }^{1}$ Сибирский фредеральный университет, Красноярск, Россия \\ ${ }^{2}$ Институт фризики им. Л.В. Киренского СО РАН - обособленное подразделение ФИЦ КНЦ СО РАН, \\ Красноярск, Россия \\ ${ }^{3}$ Федеральный исследовательский центр „Красноярский научный центр СО РАН“, Красноярск, Россия \\ 4 Калмыцкий государственный университет им. Б.Б. Городовикова, Элиста, Россия \\ 5 University of Al-Qasim Green, College of Biotechnology, Babylon, Iraq \\ E-mail: stol@iph.krasn.ru
}

Поступило в Редакцию 22 мая 2019 г.

В окончательной редакции 22 мая 2019 г.

Принято к публикации 30 мая 2019 г.

Химическое осаждение из раствора в присутствии арабиногалактана позволяет получать нанокристаллы магнетита в форме квадратных пластин с высоким аспектным отношением $(\sim 1 / 9)$. Константа магнитной анизотропии частиц в несколько раз превышает константу сферических частиц магнетита, что приводит к повышенным гистерезисным свойствам при сохранении малого объема частицы.

Ключевые слова: магнетит, наночастицы, магнитная анизотропия, полисахарид.

DOI: 10.21883/PJTF.2019.17.48220.17886

Использование ферромагнитных наночастиц для таких разделов биомедицины, как магнитная сепарация, доставка лекарств, микрохирургия, магнитная гипертермия, а также в качестве контрастных агентов в магниторезонансной томографии, ставит перед исследователями задачи, связанные с оптимизацией их магнитных свойств [1-4]. Более мелкие суперпарамагнитные частицы (с размерами до $20 \mathrm{~nm}$ ) по сравнению с более крупными ферромагнитными (частицами в заблокированном состоянии) характеризуются на порядки меньшим магнитным моментом и нулевым магнитным гистерезисом. Эта особенность суперпарамагнитных частиц облегчает получение стабильных коллоидных растворов, но существенно снижает механические и тепловые эффекты. В связи с этим представляет интерес приготовление ферромагнитных частиц возможно меньшего размера. Основной критерий стабилизации направления магнитного момента задается неравенством [5]:

$$
k_{\mathrm{B}} T<K V / \ln \left(\tau / \tau_{0}\right),
$$

где $K$ - константа магнитной анизотропии частицы, $V$ - ее объем, $T$ - температура среды, $\tau$ - характерное время использования частицы как постоянного магнита либо время измерения частицы, $k_{\mathrm{B}}-$ константа Больцмана, $\tau_{0}$ - характерное время перехода между двумя направлениями магнитного момента частицы под действием тепловых флуктуаций $\left(\sim 10^{-9} \mathrm{~s}\right)$.

Согласно (1), стабилизация при малых объемах частицы может быть достигнута только увеличением константы $K$. Такого увеличения эффективной константы магнитной анизотропии можно добиться за счет усиления вкладов от магнитокристаллической анизотро- пии [6], магнитной анизотропии формы [7], поверхностной магнитной анизотропии [8]. Для наночастиц магнетита $\left(\mathrm{Fe}_{3} \mathrm{O}_{4}\right)$, привлекательных ввиду их биосовместимости, первый вклад, связанный с химическим составом и структурой частицы, увеличивать практически невозможно. Вариация формы и поверхности частицы предоставляет возможность усиления двух оставшихся вкладов. В настоящей работе продемонстрировано, что нанокристаллы магнетита в форме квадратных пластин с высоким аспектным отношением $(\sim 1 / 9)$ характеризуются константой магнитной анизотропии, в несколько раз превышающей константу сферических частиц магнетита, что приводит к повышенным гистерезисным характеристикам при сохранении малого объема частицы.

Одним из перспективных направлений в синтезе различных типов наночастиц для биомедицины с широким спектром бактерицидных, проводящих и магнитных свойств является использование природных полисахаридов в качестве стабилизирующих и восстанавливающих агентов [9,10]. Изготовление наночастиц с помощью полисахарида возможно как в ходе одной химической реакции [9], так и в два шага, когда сначала синтезируются сами магнитные частицы, а затем их поверхность модифицируется полисахаридом [10]. Также известен метод получения таких композитных наночастиц посредством использования микроорганизмов $[11,12]$. Одним из новых полисахаридов, успешно применяемых в синтезе наночастиц, является арабиногалактан [13].

В настоящей работе наночастицы магнетита получены методом химического осаждения из сульфата железа $\left(\mathrm{FeSO}_{4} \cdot 7 \mathrm{H}_{2} \mathrm{O}\right)$ в присутствии арабиногалактана, выполняющего роль структурно-направляющего 


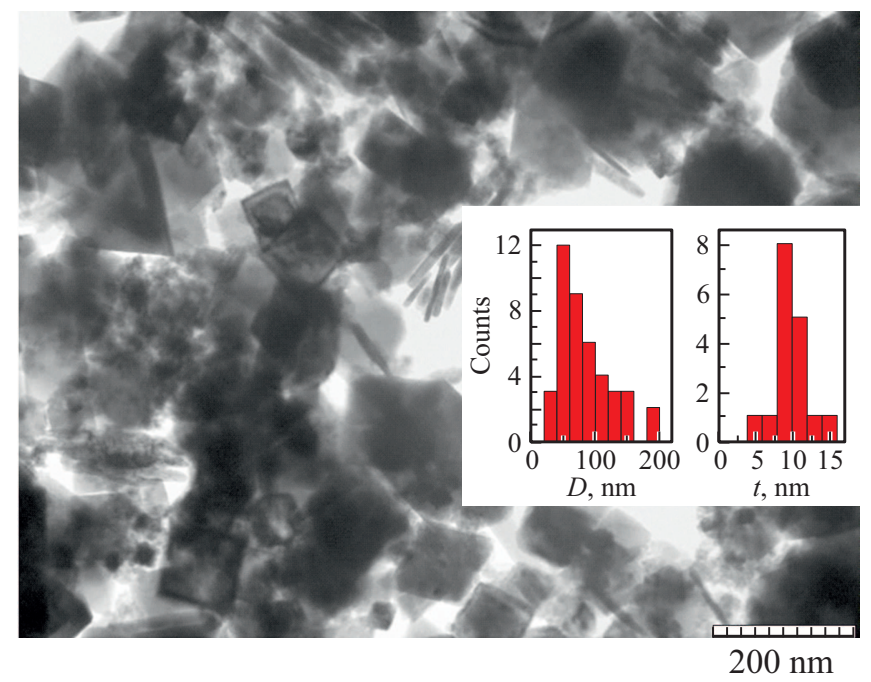

Рис. 1. ПЭМ-изображения частиц и распределение по размеру стороны квадрата $(D)$ и толщине пластины $(t)$.

и стабилизирующего агента. Необходимая температура $\left(80^{\circ} \mathrm{C}\right)$ поддерживалась с помощью водного термостата. Электронно-микроскопические исследования проводились на просвечивающем электронном микроскопе (ПЭМ) Hitachi HT7700 (ускоряющее напряжение $100 \mathrm{kV}$ ) Центра коллективного пользования Красноярского научного центра СО РАН. Измерения мессбауэровских спектров были выполнены на спектрометре $\mathrm{MC}-1104 \mathrm{Em}$ с источником ${ }^{57} \mathrm{Co}(\mathrm{Cr})$ при комнатной температуре. Статические магнитные измерения проводились на вибрационном магнитометре в интервалах полей до $6 \mathrm{kOe}$ и температур от 77 до $300 \mathrm{~K}$. Вставка с пустой капсулой, предназначенной для содержания порошка, измерялась отдельно, и ее вклад в общий сигнал $(\sim 1 \%)$ вычитался.

Электронно-микроскопические изображения (рис. 1) показывают, что наночастицы имеют форму квадратных пластин со средними размерами $90 \times 90 \times 10 \mathrm{~nm}$ (распределения частиц по толщине и ширине приведены на вставках к рис. 1). На изображениях поверхности индивидуальных пластин, полученных с высоким разрешением, видны системы кристаллических плоскостей, однородно заполняющих эту поверхность. Согласно картинам электронной дифракции и мессбауэровским спектрам, исследуемые частицы представляют собой магнетит со структурой шпинели, содержащий незначительное количество катионных вакансий $\left(\mathrm{Fe}^{3+}\right)\left[\mathrm{Fe}_{0.658}^{2+} \mathrm{Fe}_{1.228}^{3+} \square_{0.114}\right] \mathrm{O}_{4}$, где $\square$ означает катионную вакансию.

Коэрцитивная сила $H_{c}(T)$ с ростом температуры уменьшается (рис. 2), при этом $H_{c}(83 \mathrm{~K})=250 \pm 10 \mathrm{Oe}$, $H_{c}(298 \mathrm{~K})=125 \pm 10$ Ое. Учитывая, что коэрцитивное поле должно снижаться по закону $H_{c}=H_{c}(0) \times$ $\times\left(1-\left(T / T_{B}\right)^{0.77}\right)$ (где $T_{B}-$ температура блокировки), характерному для наночастиц $[14,15]$, можно оценить коэрцитивное поле при $0 \mathrm{~K}$ как $H_{c}(0)=320 \pm 20$ Ое.
Приближение намагниченности к насыщению хорошо описывается следующим выражением (см. рис. 3):

$$
M(H)=M_{s}\left(1-\frac{H_{a}^{2}}{15 H^{1 / 2}\left(H^{3 / 2}+H_{R}^{3 / 2}\right)}\right)+\chi H,
$$

предложенным для описания кривых намагничивания наночастиц оксида железа в [16] и успешно примененным в [17].

Параметры $M_{s}$ и $H_{a}$ характеризуют намагниченность и поле локальной магнитной анизотропии наночастиц и для наилучшей подгонки для комнатной температуры составляют $M_{s}=62 \pm 1 \mathrm{emu} / \mathrm{g}$ (в пересчете на объем $330 \mathrm{G}), H_{a}=3520 \pm 20$ Ое. Параметр $H_{R}$ имеет смысл обменного поля, характеризующего здесь взаимодействие магнитно-неупорядоченной поверхности и

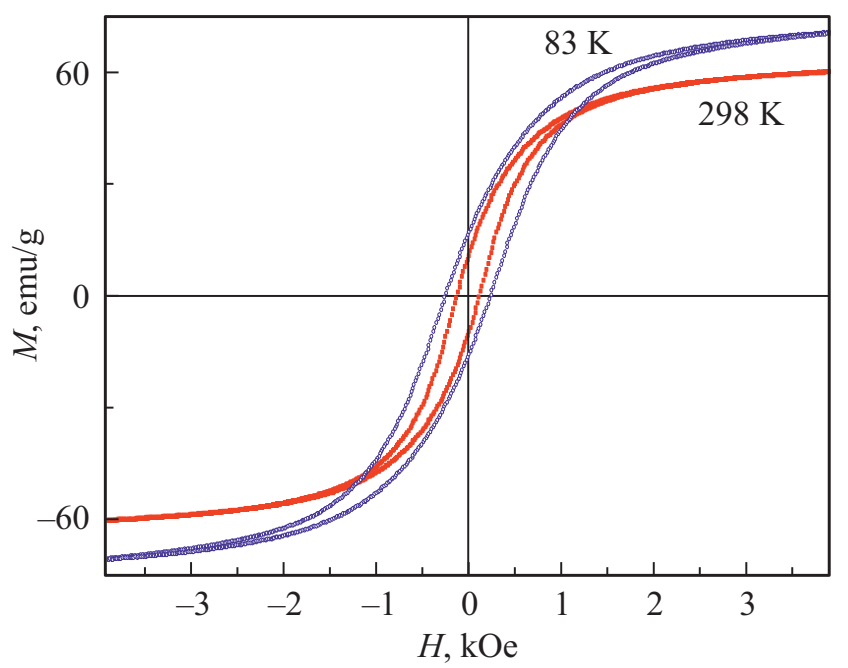

Pис. 2. Петли гистерезиса в нанокристаллах магнетита.

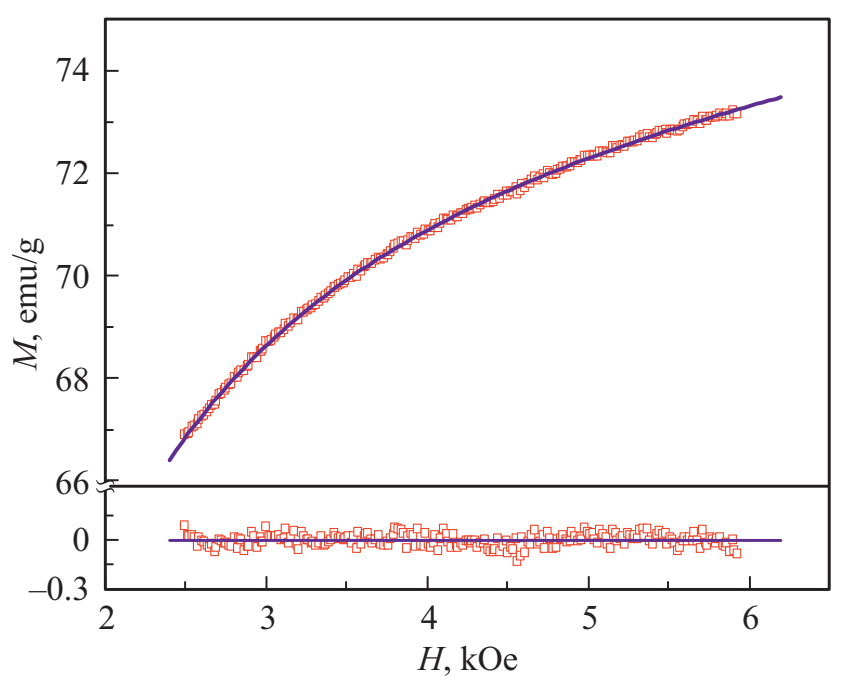

Рис. 3. Приближение намагниченности к насыщению наночастиц магнетита при $T=83 \mathrm{~K}$. Сплошная линия - наилучшая подгонка с помощью уравнения (2). Внизу показана разность теоретических и измеренных значений. 
упорядоченного ядра частицы [16] (для наилучшей подгонки кривой, измеренной при комнатной температуре, $H_{R}=2000 \pm 20$ Oе). Слагаемое $\chi H$ в формуле (2) учитывает как вклад в намагниченность от парамагнитной восприимчивости в высоких полях, так и вклад в намагниченность от спин-стекольной оболочки, характерный для наночастиц оксидов железа [18].

Константа анизотропии может быть пересчитана из поля локальной магнитной анизотропии как $K=H_{a} M_{s} / 2$. Для исследуемых частиц она составила $K=(5.81 \pm 0.16) \cdot 10^{5} \mathrm{erg} / \mathrm{cm}^{3}$. Константу анизотропии нанокристаллов в форме квадратных пластин можно оценить через сумму вкладов магнитной анизотропии формы $K_{s h}=\pi M_{s}^{2}$, магнитокристаллической анизотропии $K_{u}=1.3 \cdot 10^{5} \mathrm{erg} / \mathrm{cm}^{3}$, а также вклада поверхностной магнитной анизотропии $\left(k_{s}=2.9 \cdot 10^{-2} \mathrm{erg} / \mathrm{cm}^{2} \quad[19]\right)$. Сумма этих трех вкладов для наночастиц размером $90 \times 90 \times 10 \mathrm{~nm}$ составляет $K=6.3 \cdot 10^{5} \mathrm{erg} / \mathrm{cm}^{3}$, что хорошо согласуется с измеренной константой анизотропии. Измеренная константа анизотропии пластин в несколько раз превышает константу сферических частиц из-за значительного вклада магнитной анизотропии формы и большего вклада поверхности. Это должно приводить к тепловой стабилизации (блокировке) магнитного момента для частиц магнетита значительно меньшего объема. В таких частицах также можно ожидать более сильный магнитный гистерезис. Действительно, экспериментальная величина коэрцитивной силы $H_{c}(0 \mathrm{~K})$ составила $0.32 \mathrm{kOe}$, в то время как в сферических частицах магнетита коэрцитивная сила обычно не превышает $0.1 \mathrm{kOe}[20]$.

В заключение отметим следующее. Показано, что химическое осаждение из раствора в присутствии арабиногалактана позволяет получать нанокристаллы магнетита в форме квадратных пластин с высоким аспектным отношением ( 1/9). Константа магнитной анизотропии этих частиц в несколько раз превышает константу сферических частиц магнетита, что приводит к повышенным гистерезисным характеристикам при сохранении малого объема частицы.

\section{Финансирование работы}

Исследование выполнено при частичной финансовой поддержке Российского фонда фундаментальных исследований, Правительства Красноярского края, Красноярского краевого фонда науки в рамках научных проектов № 18-42-240006 („Наноматериалы с магнитными свойствами, определяемыми топологическими особенностями наноструктуры“) и № 18-43-243003 („Сонохимическая обработка магнитных наночастиц как способ модификации их свойств“). Работа поддержана специальной программой Министерства образования и науки РФ для Сибирского федерального университета.

\section{Конфликт интересов}

Авторы заявляют, что у них нет конфликта интересов.

\section{Список литературы}

[1] Belyanina I.V., Zamay T.N., Zamay G.S., Zamay S.S., Kolovskaya O.S., Ivanchenko T.I., Denisenko V.V., Kirichenko A.K., Glazyrin Y.E., Garanzha I.V., Grigorieva V.V., Shabanov A.V., Veprintsev D.V., Sokolov A.E., Sadovskii V.M., Gargaun A., Berezovski M.V., Kichkailo A.S. // Theranostics. 2017. V. 7. N 13. P. 3326-3337.

[2] Pankhurst Q.A., Thanh N.T.K., Jones S.K., Dobson J. // J. Phys. D.: Appl. Phys. 2009. V. 42. N 22. P. 224001.

[3] $W u W$., $W u$ Z., Yu T., Jiang C., Kim W.-S. // Sci. Technol. Adv. Mater. 2015. V. 16. N 2. P. 023501.

[4] Raikher Y.L., Stepanov V.I. // J. Magn. Magn. Mater. 2014. V. 368. P. 421-427.

[5] Néel L. // Adv. Phys. 1955. V. 4. N 14. P. 191-243.

[6] Комогориев С.В., Патрушева Т.Н., Балаев Д.А., Денисова Е.А., Пономаренко И.В. // Письма в ЖТФ. 2009. Т. 35. B. 19. C. 6-11.

[7] Комогориев С.В., Исхаков Р.С., Денисова Е.А., Балаев А.Д., Мягков В.Г., Булина Н.В., Кудашов А.Г., Окотруб А.В. // Письма в ЖТФ. 2005. Т. 31. В. 11. С. 12-18.

[8] Denisova E.A., Komogortsev S.V., Iskhakov R.S., Chekanova L.A., Balaev A.D., Kalinin Y.E., Sitnikov A.V. // J. Magn. Magn. Mater. 2017. V. 440. P. 221-224.

[9] Chang P.R., Yu J., Ma X., Anderson D.P. // Carbohydr. Polym. 2011. V. 83. N 2. P. 640-644.

[10] Khmara I., Strbak O., Zavisova V., Koneracka M., Kubovcikova M., Antal I., Kavecansky V., Lucanska D., Dobrota D., Kopcansky P. // J. Magn. Magn. Mater. 2019. V. 474. P. 319 325.

[11] Baldi F., Marchetto D., Battistel D., Daniele S., Faleri C., De Castro C., Lanzetta R. // J. Appl. Microbiol. 2009. V. 107. N 4. P. $1241-1250$.

[12] Балаев Д.А., Красиков А.А., Дубровский А.А., Баюков О.А., Столяр С.В., Исхаков Р.С., Ладыгина В.П., Ярославщев Р.Н. // Письма в ЖТФ. 2015. Т. 41. В. 14. C. $88-96$.

[13] Petrova M.V., Kiryutin A.S., Savelov A.A., Lukzen N.N., Vieth H.-M., Yurkovskaya A.V., Bogomyakov A.S., Aleksandrova G.P., Sukhov B.G., Trofimov B.A., Ovcharenko V.I. // Appl. Magn. Res. 2011. V. 41. N 2-4. P. 525-536.

[14] Poperechny I.S., Raikher Y.L., Stepanov V.I. // Physica B. 2014. V. 435. P. 58-61.

[15] Pfeiffer H. // Phys. Status Solidi A. 1990. V. 118. N 1. P. 295 306.

[16] Safronov A.P., Beketov I.V., Komogortsev S.V., Kurlyandskaya G.V., Medvedev A.I., Leiman D.V., Larrañaga A., Bhagat S.M. // AIP Adv. 2013. V. 3. N 5. P. 052135.

[17] Devi E.C., Soibam I. // J. Alloys Compd. 2019. V. 772. P. 920 924.

[18] Kodama R.H., Berkowitz A.E., McNiff E.J., Jr., Foner S. // Phys. Rev. Lett. 1996. V. 77. N 2. P. 394-397.

[19] Pérez N., Guardia P., Roca A.G., Morales M.P., Serna C.J., Iglesias O., Bartolomé F., García L.M., Batlle X., Labarta A. // Nanotechnology. 2008. V. 19. N 47. P. 475704.

[20] Lee J.S., Cha J.M., Yoon H.Y., Lee J.-K., Kim Y.K. // Sci. Rep. 2015. V. 5. N 1. P. 12135. 